\title{
SLEEPINESS AND DAILY SLEEP OF MALAYSIAN SHIFT WORKERS IN ELECTRONICS MANUFACTURING INDUSTRY
}

\author{
Mohd Shahril AH, Mohamad Ezuan AJ and Norazura I* \\ Faculty of Engineering Technology, Universiti Malaysia Pahang, Lebuhraya Tun Razak, 26300 Gambang, Kuantan, \\ Malaysia
}

* Corrensponding author: Norazura Ismail
Email address: zuraismail@ump.edu.my

ABSTRACT

The purpose of this study was to identify the relationship between sleepiness and daily sleep amount, and its significant associated factors among shift workers of the electronics manufacturing industry in Malaysia. 300 shift workers were asked to respond to a survey on demographic information, sleepiness and daily sleep. Sleepiness was surveyed by using the Karolinska Sleepiness Scale and daily sleep was captured by using sleep diary. A total of 255 employees provided valid data for analysis. To test the hypothesis, statistical analysis was conducted using IBM SPSS program version 24. Sleepiness among shift workers found to be increased by the end of the shift. Around $30 \%$ of workers did not have an adequate amount of daily sleep. Sleepiness was found to have significant associations with age, marital status, level of education, time of shift, and working experience. Meanwhile, the amount of daily sleep obtained was only significantly associated with the age of the respondents. There is no significant relationship found between sleepiness and daily sleep of the shift workers. Shift workers in the electronics manufacturing industry in Malaysia were exposed to sleepiness at work and reduction in their daily sleep. This will increase the risk of an accident in the workplace. Appropriate intervention program should be implemented to curb this problem.

Keywords: Sleepiness, shift work, shift workers, sleep, safety, manufacturing, Malaysia.

\section{INTRODUCTION}

A quarter of the workforce worldwide are working outside normal daytime of employment time as there is an increasing demand by the community for society to operate 24/71. Examples of features that emerge due to these demands are shift work and night-work that shaping the occupational market and experienced by millions of employees globally on a regular basis. The increasing number of shift workers especially in manufacturing industries resulted in an increasing number of individuals who become affected by the physical and social environments at the workplace. Due to the degree and nature of working time implemented by this workplace, it contributes to a number of negative consequences both for the occupational and behavioural health of the workers ${ }^{2}$.

Shift work is defined as any type of employment where employees are required to work during usual sleeping time ${ }^{3}$. The most common shift work method employed by an organization may include a 12 hours day and night shift rosters, where 2 panels of employees work for 12 hours during day or night shift with 12 hours breaks or 8 hours rosters where 3 panels of employees work 8 hours in the morning, evening, or night shift with 16 hours breaks. All shift work commonly combines two of the main risk factors for occupational injuries and accidents risk, circadian misalignment and prolonged sleeplessness especially for shift workers who work during the evening and night shifts ${ }^{4}$.
The most predominant effects of shift work are those linked to sleeping disturbance, loss of sleep, sleepiness and fatigue, which can decrease the quality of life, work efficiency and safety of the workers ${ }^{2}$. Work hours that result in altered sleeping times may cause disruption to sleep, shortened sleeping duration and sleepiness due to disruption to the body's circadian system ${ }^{5}$. Changes that happened to shift workers also greatly impairs their ability to sleep, resulted into insomnia, accumulation of sleep debt and daytime sleepiness that required long recovery period ${ }^{6-7}$. Shift workers also have a higher risk of acquiring acute and chronic conditions such as cardiovascular disease, type 2 diabetes, obesity, hypertension, stomach related problems, anxiety, and depression ${ }^{8}$.

Sleepiness can be described as a culmination of circadian factors, pre-wakefulness duration, prior sleep duration, and workload that received by the workers ${ }^{9}$. The gradual development sleepiness will occur after a period of prolonged sleeplessness. This usually paired together with a reduction in mental and physical performance, including a reduction in attentiveness and reaction times among the workers 10-11. Shift workers will also experience reduced sleeping period and sleep quality that can further aggravate sleepiness. Sleepiness not only affects shift workers but a great number of regular people in a population, and is typically related to intermittent sleep, and is connected to the rise of the risk of accidents ${ }^{12-13}$. 
As electronic manufacturing industry is one of the largest contributors to Malaysia Gross Domestic Product (GDP) value and the number of shift workers in Malaysia, this study was conducted by focusing specifically on this industry. Furthermore, as there is limited research in Malaysia on the effect of shift work on worker's sleepiness and daily sleep, this study could fill the gap. The purpose of this study was to investigate the level of sleepiness and the amount of daily sleep obtained by the shift workers, the factors that can affect the sleepiness and daily sleep of shift workers, and the relationship between sleepiness and daily sleep of shift workers in electronics manufacturing industry.

\section{METHODS}

\section{Participants and procedure}

A cross-sectional study was carried out in an electronic manufacturing factory in Malaysia. A list of workers was obtained from the Human Resource Department to be recruited as respondents. The respondents were selected based on the inclusion criteria set by the researchers: (1) aged 18 years or older; (2) at least have 1-year working experience in the manufacturing industry; (3) working in a shift; and (4) did not have any sleep-related illness. 300 workers were selected as respondents by using a simple random sampling technique. However, only 255 workers participated in this study as 15 workers did not meet the inclusion criteria and were excluded, and 30 workers declined to participate in the study.

\section{Measurement}

A general questionnaire was distributed among 300 shift workers to ascertain their background information. The questionnaire comprised of three parts: 1) demographic factors (gender, age, marital status, education level and body mass index), 2) work-related factors (shift, overtime and working experience), and 3) lifestyle factors (daily smoking, alcohol consumption, caffeine consumption and exercise routine).

Subjective sleepiness during the shift work was measured by using the Karolinska Sleepiness Scale (KSS) that was adapted to Bahasa Malaysia. KSS is as a nine-point scale that was established to measures the level of sleepiness among respondent subjectively at a particular given time ${ }^{14}$. In this measurement, subjects specify which score best represents their sleepiness state experienced in the last $10 \mathrm{~min}$. A worker was described as "severely sleepy" if the KSS score values were greater than 6 . In this study, respondents were asked to rate their sleepiness during the start, middle, and end of the shift for five days during their entire week of a shift.
Workers' daily sleep was measured as the time the respondent spent sleeping daily including the nap time taken for the day. It was assessed by using a sleep diary that required the respondent to jot down the time of sleep and time of awake. Sleeping time was measured as sufficient if the total daily sleep (combining daily main and nap sleep) preceding a shift was 6 hour or more. Respondents were asked to record their sleeping pattern including their nap time for the entire week of working in shift (5 days).

\section{Data Analysis}

IBM SPSS version 24 was used to analyse the data. Descriptive analysis was used to demonstrate the characteristics and features of the study population. Chi-square test was conducted to find the association between categorical variables. Pearson correlation analysis was conducted for continuous data to find a significant relationship between the variables.

\section{RESULT}

\section{Respondents' Characteristics}

The characteristics of the respondents were shown in Table 1. For demographic factors, all of the respondents were female $(100 \%)$, half of them below 29 years old $(54.9 \%)$, single $(58.8 \%)$, have normal Body Mass Index (BMI) (53.3\%), and finish high school (60.4\%). Under the job characteristics, most of the respondents working in day shift (76.1\%), did not work overtime (40\%) and have working experience less than 6 years (46.7\%). In the social factors, all respondents did not drink alcohol (100\%), did not smoke (100\%), half of them did not consume caffeine $(51.4 \%)$, and most of them did not exercise regularly $(75.7 \%)$.

\section{Sleepiness and daily sleep}

The sleepiness and daily sleep of the respondents was shown in Table 2 and 3. According to table 2, we can see that $84.3 \%$ of the shift workers have an adequate amount of sleep. An adequate amount of sleep was considered when workers get at least 6 hours of daily sleep. Table 3 show workers' sleepiness according to the time of the shift. Workers were considered sleepy if the rating that they recorded were at least at 7 . On average, none of the workers has scored more than 6 and $40 \%$ of them recorded score 3 that considered as not sleepy. When the sleepiness was measured based on the time of the shift, we can see the increase of score from the start to the end of the shift. At the start of the shift, no workers recorded score more than 6 , but it increased to 8 workers $(3.2 \%)$ in the middle of the shift, and to 17 workers $(6.7 \%)$ by the end of the shift. 
Malaysian Journal of Public Health Medicine 2020, Special Volume 1: 208-215

Table 1 Characteristics of the respondents $(\mathrm{N}=255)$

\begin{tabular}{|c|c|c|c|}
\hline Characteristics & Category & Frequency & Percentage (\%) \\
\hline \multirow[t]{4}{*}{ Age } & $<29$ & 140 & 54.9 \\
\hline & $30-39$ & 51 & 32.9 \\
\hline & $40-49$ & 18 & 7.1 \\
\hline & $>50$ & 46 & 18.1 \\
\hline \multirow[t]{3}{*}{ Marital Status } & Single & 150 & 58.8 \\
\hline & Married & 82 & 32.2 \\
\hline & Divorce & 23 & 9.0 \\
\hline \multirow[t]{4}{*}{ Body Mass Index } & Underweight & 23 & 9.0 \\
\hline & Normal & 136 & 53.3 \\
\hline & Overweight & 49 & 19.2 \\
\hline & Obese & 47 & 18.5 \\
\hline \multirow[t]{4}{*}{ Education Level } & Primary School & 33 & 12.9 \\
\hline & Middle School & 40 & 15.7 \\
\hline & High School & 154 & 60.4 \\
\hline & Diploma & 28 & 11.0 \\
\hline \multirow[t]{2}{*}{ Shift } & Day & 194 & 76.1 \\
\hline & Night & 61 & 23.9 \\
\hline Overtime & 0 & 102 & 40 \\
\hline \multirow{3}{*}{ (hours/day) } & $1-2$ & 76 & 29.80 \\
\hline & $3-4$ & 37 & 14.51 \\
\hline & $>4$ & 40 & 15.69 \\
\hline \multirow{4}{*}{$\begin{array}{l}\text { Work Experience } \\
\text { (years) }\end{array}$} & $<6$ & 119 & 46.7 \\
\hline & $6-10$ & 44 & 17.3 \\
\hline & $11-15$ & 23 & 9.0 \\
\hline & $>15$ & 69 & 27.0 \\
\hline \multirow[t]{2}{*}{ Caffeine } & Yes & 124 & 48.6 \\
\hline & No & 131 & 51.4 \\
\hline \multirow[t]{2}{*}{ Exercise } & Yes & 62 & 24.3 \\
\hline & No & 193 & 75.7 \\
\hline
\end{tabular}

Notes: all respondents were female, did not smoke and did not consume alcohol.

Table 2 Daily sleep among respondents

\begin{tabular}{ccccccc}
\hline $\begin{array}{c}\text { Sleep } \\
\text { Amount } \\
\text { (Hours) }\end{array}$ & $\begin{array}{c}\text { Average } \\
\text { Frequency } \\
(\%)\end{array}$ & $\begin{array}{c}\text { Day 1 } \\
\text { Frequency } \\
(\%)\end{array}$ & $\begin{array}{c}\text { Day 2 } \\
\text { Frequency } \\
(\%)\end{array}$ & $\begin{array}{c}\text { Day 3 } \\
\text { Frequency } \\
(\%)\end{array}$ & $\begin{array}{c}\text { Day 4 } \\
\text { Frequency } \\
(\%)\end{array}$ & $\begin{array}{c}\text { Day 5 } \\
\text { Frequency } \\
(\%)\end{array}$ \\
\hline 1 & $0(0)$ & $0(0)$ & $0(0)$ & $0(0)$ & $0(0)$ & $0(0)$ \\
2 & $0(0)$ & $1(0.4)$ & $0(0)$ & $0(0)$ & $0(0)$ & $0(0)$ \\
3 & $2(0.8)$ & $3(1.2)$ & $2(0.8)$ & $1(0.4)$ & $1(0.4)$ & $2(0.8)$ \\
4 & $3(1.2)$ & $13(5.1)$ & $12(4.7)$ & $5(2.0)$ & $10(3.9)$ & $12(4.7)$ \\
5 & $35(13.7)$ & $38(14.9)$ & $34(13.3)$ & $40(15.7)$ & $41(16.1)$ & $36(14.1)$ \\
6 & $104(40.8)$ & $84(32.9)$ & $92(36.1)$ & $93(36.5)$ & $89(34.9)$ & $101(39.6)$ \\
7 & $89(34.9)$ & $76(29.8)$ & $78(30.6)$ & $88(34.5)$ & $76(29.8)$ & $75(29.4)$ \\
8 & $22(8.6)$ & $39(15.3)$ & $35(13.7)$ & $26(10.2)$ & $36(14.1)$ & $28(11.0)$ \\
9 & $0(0)$ & $1(0.4)$ & $2(0.8)$ & $2(0.8)$ & $2(0.8)$ & $1(0.4)$ \\
\hline
\end{tabular}

Table 3 Sleepiness among respondents

\begin{tabular}{ccccc}
\hline Karolinska Scale & $\begin{array}{c}\text { Average } \\
\text { Frequency (\%) }\end{array}$ & $\begin{array}{c}\text { Start } \\
\text { Frequency (\%) }\end{array}$ & $\begin{array}{c}\text { Middle } \\
\text { Frequency (\%) }\end{array}$ & $\begin{array}{c}\text { End } \\
\text { Frequency (\%) }\end{array}$ \\
\hline 1 & $5(2.0)$ & $77(30.2)$ & $5(2.0)$ & $28(11.0)$ \\
2 & $42(16.5)$ & $81(31.8)$ & $17(6.7)$ & $35(13.7)$ \\
3 & $102(40.0)$ & $76(29.8)$ & $66(25.9)$ & $82(32.2)$ \\
4 & $82(32.2)$ & $14(5.5)$ & $66(25.9)$ & $42(16.5)$ \\
5 & $22(8.6)$ & $6(2.4)$ & $53(20.8)$ & $26(10.2)$ \\
6 & $2(0.8)$ & $1(0.4)$ & $40(15.7)$ & $25(9.8)$ \\
7 & $0(0)$ & $0(0)$ & $6(2.4)$ & $15(5.9)$ \\
8 & $0(0)$ & $0(0)$ & $2(0.8)$ & $1(0.4)$ \\
9 & $0(0)$ & $0(0)$ & $0(0)$ & $1(0.4)$ \\
\hline
\end{tabular}




\section{Associated factors for sleepiness and daily sleep}

Table 4 shows the results of the association of respondents' characteristics on workers' sleepiness and daily sleep. Sleepiness have significant association with age $\left(x^{2}=11.407, \mathrm{p}=\right.$ $0.010)$, marital status $\left(x^{2}=7.568, p=0.023\right)$, education level $\left(x^{2}=11.813, p=0.008\right)$, shift $\left(x^{2}=\right.$ $8.250, p=0.004)$, and working experience $\left(x^{2}=\right.$ 9.696, $p=0.046)$. As for daily sleep, it is only significantly associated with the age of the respondent $\left(x^{2}=8.308, p=0.040\right)$.

\section{Relationship between sleepiness and daily sleep}

Relationship between sleepiness and daily sleep was analysed by using Pearson Correlation test. Table 5 shows the result of the test. It is found that there is no significant correlation between sleepiness score and daily sleep of the respondents.

Table 4 Association of respondents' characteristics with sleepiness and daily sleep

\begin{tabular}{lcccc}
\hline \multicolumn{1}{c}{ Variables } & \multicolumn{2}{c}{ Sleepiness } & \multicolumn{2}{c}{ Daily Sleep } \\
& $x^{2}$ & $\mathrm{p}$-value & $x^{2}$ & $\mathrm{p}$-value \\
\hline Age & 11.41 & $0.01^{* *}$ & 8.31 & $0.04^{*}$ \\
Marital Status & 7.57 & $0.02^{*}$ & 2.63 & 0.27 \\
BMI & 6.29 & 0.10 & 2.87 & 0.41 \\
Education Level & 11.81 & $0.01^{* *}$ & 3.80 & 0.28 \\
Shift & 8.25 & $0.00^{* *}$ & 2.73 & 0.44 \\
Overtime & 3.87 & 0.28 & 1.25 & 0.74 \\
Working experience & 9.70 & $0.04^{*}$ & 6.87 & 0.14 \\
Caffeine & 1.34 & 0.25 & 2.18 & 0.54 \\
Exercise & 0.28 & 0.60 & 4.97 & 0.17 \\
\hline
\end{tabular}

Notes: ${ }^{*}=$ significant at $p=0.05,{ }^{* *}=$ significant at $p=0.01$

Table 5 Relationship between sleepiness and daily sleep

\begin{tabular}{lccc}
\hline \multicolumn{1}{c}{ Variables } & & Daily Sleep & \\
& $r$ & & $\mathrm{p}$-value \\
\hline Sleepiness & 0.01 & 0.83 \\
\hline
\end{tabular}

\section{DISCUSSION}

Shift workers have an increased risk of having problems in falling asleep, and these difficulties of sleeping found to being reduced after workers stop work in shift system ${ }^{15}$. The result shows that only a small percentage of workers have daily sleep less than 6 hours, an amount that considered sufficient for workers to fully function for the next day. The result also shows that only a small percentage of workers were severely sleepy with having scored more than 6 and a third of them were having mild sleepiness (a score between 3 and 6 ). Based on the time of the shift, there was an increased number of sleepy workers by the end of the shift when compared with when they start the shift where the percentage increase from $0 \%$ to $6.7 \%$. When compared with this study, the percentage of sleepiness measured among workers in other studies were varies from one country to another which is between $1 \%-3 \%$ in the United States, 10\% in France and about 33\% in Australia $^{16}$.

In this study, it is found that age, marital status, education level, shift time, and working experience have a significant effect on sleepiness and age have a significant association with the daily sleep of shift workers. Older workers did not have adequate ability to recover from shift work effects when compared with younger people. This is due to a decrement in the concentration of melatonin that required for the sleep-wake cycle ${ }^{17}$. Thus, they will spend more effort in adjusting the circadian rhythm to night work causing an increase in sleep-related conditions including sleepiness at work and also reduced the number of sleep period obtained ${ }^{18}$. Majority of studies conclude that age is related to sleepiness where older workers were more impaired in their sleeping quality and at risk of excessive sleepiness when compared to younger workers ${ }^{19}$.

In BMI as a risk factor, similar to this study, out of the eight related studies, $62.5 \%$ of them reported no significant difference in sleeping problems based on the shift workers' weight ${ }^{19}$. Farzianpour $(2016)^{20}$ in his study on the shift nurse found that educated workers had better sleep when compared with lower education workers. Based on the systematic review performed by Booker et al. $(2018)^{19}$ on healthcare system workers that involved with shift work, the impact of working experience on sleep was divided among researcher. In this review, four studies reported that experienced shift workers have healthier sleep when compared to newer shift workers, five studies found that experienced workers have poor sleep and four studies found no difference. One of the possible theories for the differences found in 
the studies might come from people ability in learning to handle their shift work with experience, so over time through experience, workers develop their own coping strategies ${ }^{21}$. Moreover, workers who did not survive shift work environment are likely to quit a job that requires them to work in shift system ${ }^{22}$.

In this study, marital status and time of shift found to have a significant effect on workers' sleepiness level. Portela $(2015)^{23}$ on his study on shift nurse found that married workers had poorer sleep when compared with single workers. This finding also supported by Booker et al. $(2018)^{19}$ in his systematic review. He found that half of the studies stated that people with children were associated with poorer sleep contrasted to single people or married with no kids. Other similar studies also generally find that night shift workers are associated with a greater incidence of disturbed sleep compared to those working during the day shift $24-27$. Daily sleep obtains by workers after night shifts also found to be reduced by onethird and main sleep before the morning shifts reduced by about 2 hours $^{28}$. Cotrim et al. (2017) ${ }^{29}$ on his study on shift railway workers found a high sleepiness prevalence $(72.2 \%)$ during the night shift when compared with day shifts.

It is important to assess, treat, and prevent daytime sleepiness among shift workers in order to reduce the risk of workplace injuries ${ }^{30}$. One of the possible ways to prevent sleepiness is to take a nap or short sleep during work time. Naps or short sleep have been found as a possible preventive measure to sleepiness and shown to have restorative value after sleepiness. Short naps during daytime are capable to diminish lethargy and improving working time function in sleepless workers ${ }^{31}$. Short sleep around 10 minutes has been shown to boost attentiveness and workers' performance especially an hour after the nap. Other strategies that found to be popular including modification of shift length, caffeine intake, and regular mental and physical exercise $^{32}$. Other than that, most studies suggest workplace educational interventions as a beneficial way to improve alertness and mitigate sleepiness among shift workers ${ }^{33}$.

\section{REFERENCES}

1. Wyatt WB. Shift work and the assessment and management of shift work disorder (SWD). Sleep Med Rev 2013; 17(1): 41-54.

2. Smith L, Tanigawa T, Takahashi M, Mutou $\mathrm{K}$, et al. Shiftwork locus of control, situational and behavioral effects on sleepiness and fatigue in shift workers. Industrial Health 2005; 43: 151-170.

3. American Academy of Sleep Medicine. International classification of sleep
This study had several limitations. Due to the type of study was cross-sectional, causality between factors cannot be established. It is advisable that future research to apply another type of research where the various factors and study variable could be manipulated to assess the cause-effect relationship. Another limitation of the study was the usage of the self-report method in obtaining data and the lack of objective measures to anchor the self-reported findings. Even though the method used had high reliability and already established method, there was still the possibility of information bias as some respondents may refuse to provide an honest response. For future research, it is recommended that both subjective and objective measurement used concurrently in a study to obtain the most accurate results. The last limitation of this study is the small sample size as the size could only represent the factory population but cannot represent the whole manufacturing workers population in Malaysia. The larger sample size that can represent the actual working population should be considered in future studies.

\section{CONCLUSION}

In conclusion, shift workers were exposed to sleepiness especially at the end of their working shift and a third of them did not obtain adequate daily sleep. There were various factors associated with this development such as age, marital status, education level, shift time, and working experience. As sleepiness and reduced daily sleep among shift workers represent a threat to the workers' safety performance, appropriate intervention strategies should be proposed to reduce the occurrence of sleepiness and increase the amount of daily sleep obtained by the shift workers. This study also contributes to the theoretical and practical understanding of the effects of demographic, work, and social factors on sleepiness and daily sleep of shift workers in the electronics manufacturing industry in Malaysia.

\section{ACKNOWLEDGEMENT}

This study was supported by University Malaysia Pahang grant: RDU190305

disorders: diagnostic and coding manual, ICSD-3. 3rd ed. Darien, IL: American Academy of Sleep Medicine 2014.

4. Folkard S, Lombardi D, Tucker P. Shiftwork: Safety, sleepiness and sleep. Industrial Health 2005; 43: 20 -23.

5. Sneddon A, Mearns K, Flin R. Stress, fatigue, situation awareness and safety in offshore drilling crews. Safety Science 2013; 56: 80-88. 
6. Simon R. Shift work disorder: clinical assessment and treatment strategies. $J$ Clin Psyc 2012; 73(6): 20-32.

7. Roth T. Appropriate therapeutic selection for patients with shift work disorder. Sleep Med 2012; 13(4): 335-341.

8. Antunes LC, Jornada MN, Ramalho L, Hidalgo MP. Correlation of shift work and waist circumference, body mass index, chronotype and depressive symptoms. Arq Bras Endo Metabol 2010; 54(7): 652-666.

9. Williamson AM, Feyer A, Mattick RP, et al. Developing measures of fatigue using an alcohol comparison to validate the effects of fatigue on performance. Accident Analysis and Prevention 2001; 33: 313326.

10. Dorrian J, Lamond N, Dawson D. The ability to self-monitor performance when fatigued. J Sleep Res 2000; 9(2): 137-144.

11. Howard ME, Radford L, Jackson ML, et al. The effects of a 30-minute napping opportunity during an actual night shift on performance and sleepiness in shift workers. Biological Rhythm Research 2010; $41(2)$ : 137-148.

12. Ohayon MM. Determining the level of sleepiness in the American population and its correlates. J Psychiatr Res 2012; 46: 422-427.

13. Philip P, Akerstedt T. Transport and industrial safety, how are they affected by sleepiness and sleep restriction?. Sleep Med Rev 2006; 10: 347-356.

14. Akerstedt T, Gillberg M. Subjective and objective sleepiness in the active individual. Int J Neuro 1990; 52: 29-37.

15. Nordin $M$, Alfredsson L, Westerholm P. Sleep and sleepiness: impact of entering or leaving shiftwork - a prospective study. Chronobiology International 2010; 27(5): 987-996.

16. Bener A, Yildirim E, Ozkan T, Lajunen T. Driver sleepiness, fatigue, careless behaviour and risk of motor vehicle crash and injury: population based case and control study. J Traffic Transp Eng 2017; 4(5): $496-502$.

17. Costa G, Sartori S. Ageing, working hours and work ability. Ergonomics 2007; 50(11): 1914-1930.

18. Flo E, Pallesen S, Moen BE, et al. Short rest periods between work shifts predict sleep and health problems in nurses at 1year follow-up. Occup Environ Med 2014; 71(8): 555-561.

19. Booker LA, Magee M, Rajaratnam SMW, et al. Individual vulnerability to insomnia, excessive sleepiness and shift work disorder amongst healthcare shift workers. A systematic review. Sleep Med Rev 2018; 41: 220-233.

20. Farzianpour F, Nosrati SA, Foroushani AR, et al. Relationship between shift work and personality traits of nurses and their coping strategies. Global J Health Sci 2016; 8(5): 166-174.

21. Chou TL, Chang LI, Chung $\mathrm{MH}$. The mediating and moderating effects of sleep hygiene practice on anxiety and insomnia in hospital nurses. Int $J$ Nurs Pract 2015; 21(Suppl. 2): 9-18.

22. West SH, Ahern M, Byrnes M, Kwanten L. New graduate nurses adaptation to shift work: can we help?, J Roy Coll Nurs Aust 2007; 14(1): 23-30.

23. Portela LF, Kroning Luna C, Rotenberg L, et al. Job strain and self-reported insomnia symptoms among nurses: what about the influence of emotional demands and social support?. Bio Med Res Int 2015; 1-8.

24. Akerstedt $T$, Ingre $M$, Broman JE, Kecklund G. Disturbed sleep in shift workers, day workers, and insomniacs. Chronobiol Int 2008; 25: 333-348.

25. Conway PM, Campanini P, Sartori S, et al. Main and interactive effects of shiftwork, age and work stress on health in an Italian sample of healthcare workers. Appl Ergon 2008; 39: 630-639.

26. Drake CL, Roehrs T, Richardson G, et al. Shift work sleep disorder: prevalence and consequences beyond that of symptomatic day workers. Sleep 2004; 27: 1453-1462.

27. Ursin R, Baste V, Moen BE. Sleep duration and sleep-related problems in different occupations in the Hordaland Health Study. Scand J Work Environ Health 2009; 35: 193-202.

28. Sallinen $M$, Harma $M$, Mutanen $P$, et al. Sleepiness in various shift combinations of irregular shift systems. Ind Health 2005; 43(1): 114-122.

29. Cotrim T, Carvalhais J, Neto C, et al. Determinants of sleepiness at work among 
railway control workers. Applied Ergonomics 2017; 58: 293-300.

30. Melamed S, Oksenberg A. Excessive daytime sleepiness and risk of occupational injuries in non-shift daytime workers. Sleep 2002; 25: 315-22.

31. Takahashi M, Arito $H$. Maintenance of alertness and performance by a brief nap after lunch under prior sleep deficit. Sleep 2000; 23(6): 813-819.

32. Ker K, Edwards PJ, Felix LM, et al. Caffeine for the prevention of injuries and errors in shift workers. Cochrane Database Syst Rev 2010; 12(5)

33. Gander PH, Marshall NS, Bolger W, Girling I. An evaluation of driver training as a fatigue countermeasure. Transp Res Part F: Traffic Psychol Behav 2005; 8(1): 47-58 
